\title{
Human Cloning from the Taoist Viewpoint
}

\author{
YU Ru-song \\ School of History and Culture, Shandong University, Jinan, China
}

\begin{abstract}
Although human cloning represents the latest development of modern biotechnology, it still has many limitations that are difficult to overcome. Human cloning involves asexually reproduced human life, may involve some degree of genetic determinism, and makes human life subject to objectification and commercialization. Therefore, a cloned human being will certainly lose the dignity due to him as a human being. Taoism, regarded as the successful combination of religious humanistic care and scientific rationality, advocates the natural reproductive process, while insisting on the unity of body and mind. Besides physical care, Taoism takes the demands of human beings’ transcendental nature into account. Therefore, Taoism may be a source of great inspiration and guidance for the future development of human cloning.
\end{abstract}

Keywords: Taoism, human cloning, Enlightenment

Since the Enlightenment, science and technology have been developing at an unprecedented rate and impacted every aspect of human life. The rapid rise of modern biotechnology makes it generally believed that 21st century will be the "biotech century." The most unusual feature of this coming biotech century may be that human himself might become the direct manufacturing object processed by biotechnology. And so, human cloning, having been considered as a "Biotic A-bomb" or "Ethical Bomb” (HAN Xiaocheng, 2005, p. 44), is attracting the world's attention in particular.

I bring this paper to birth in the hope of that it could make it clear that science and technology should be of more humanistic spirit and care, just like religion, to benefit but not to harm human and the society during the process of their development and application, and that in human reproduction, human cloning will be certain to do more harm than good from the Taoist viewpoint.

\section{The Intrinsic Essence of Human Cloning}

Cloning technology involves transplanting the nucleus of a mature somatic cell into an egg cell whose nucleus has been removed to create the biological equivalent of a zygote, from which an embryo may develop, then implanting the embryo into the uterus of a surrogate mother to develop into a cloned being that would become a genetic replica of the somatic cell donor.

Human cloning is divided into two categories in terms of its goals: therapeutic and reproductive. The goal of therapeutic cloning is to obtain stem cells from the unimplanted embryo produced in the hope of producing corresponding cells, tissues, or whole organs for the purpose of medical research or transplantation without fear of immunological rejection. The goal of reproductive cloning is to produce a born child. The key difference 
between these two types of cloning is that the embryo used for therapeutic cloning does not develop beyond the 14-day mark. Generally speaking, therapeutic cloning is considered legitimate, while the reproductive one is illegal (HAN Yuehong, 2005, pp. 268-272). In this paper, the term "human cloning” mainly refers to reproductive cloning.

Despite opposition from many quarters, human cloning has been developing irresistibly, resulting from the unique inertial character of science and technology. As such, it has been approaching the reality of human life, which has raised many concerns. The intrinsic essence of human cloning can be summarized as follows:

(1) Manipulating human reproduction artificially and creating a being based upon subjective values;

(2) Asexual propagation involving either a single progenitor, or up to three (somatic nucleus donor, egg donor, gestational mother) involved in the reproductive process;

(3) The cloned infant having the same genetic identity as the donor; life's biological connotation, or biochemical composition becoming the focus of human cloning attention.

(4) Human beings are created and operated upon as the object and purpose of biotechnology, which results in objectification, instrumentalization, and perhaps even commercialization.

In a word, all in the procedure of human cloning is artificially done under human intentions. So reproductive cloning can be regarded as a product affected by genetic determinism; by utilizing intentional genetic design, human cloning attempts to manipulate genes artificially, control the genomes of organisms, and facilitate asexual reproduction, resulting in both "man-made" and "man-making” products. As such, cloning runs the risk of reducing human life to merely its biological foundation.

\section{Human Reproduction from the Taoist Perspective}

Taoists believe that the Tao is non-being, which is infinite and absolutely abstract; it is everything's sacred origin and ultimate destination. Every life is the result of the natural combination of Yin and Yang. The real meaning of life does not just lie in the favor of secularity but that of the unity of life and Tao.

First, with respect to life coming into being, Taoists conceive of the transcendent Tao as having conceived some kind of Tao Qi or Jing Qi similar to the gene, which is the basis for producing life. The Tao Te Ching states:

Great Virtue is manifested by following only Tao. Tao as being is merely impalpable and incommensurable. Incommensurable and impalpable, yet forms are latent in it; Impalpable and incommensurable, yet entities are within it. Tao is also shadowy and dim, yet energy has been within it; its energy is rarefied but real, which can be relied on and believed in. (Tao Te Ching 21)

In the birth and development of lives, Tao is the foundation upon which all things depend for their existence. Tao connotes mysterious dark energy, and it is impalpable, incommensurable and unpredictable, beyond human ability to comprehend. Tao has congenitally implied forms, entities and energy, which has a holographic connotation, similar to genetic information contained in cells in modern biology. Tao is thus a kind of matrix, potential and power for life to be born and evolve naturally.

Next, Taoism upholds the basic principle in Chinese traditional culture of the balance between the negative (Yin) and the positive (Yang); all lives are a product of the balance between Yin and Yang, as the Tao Te Ching states: "Everything keeps Yin and Yang together internally as its content, and balances the two to be harmonious externally as its form” (Tao Te Ching 42). As for the specific human life to be reproduced, Taoists believe that the 
harmony of Yin and Yang also refers to the natural combination of male sperm (Jing) and female egg (Blood or Xue). Tao Sheng Zhi (written in the late of Tang Dynasty) states: "Fundamentally speaking, human origins from the combination of male's Jing and female's Xue, and follows Tao to be born naturally."1 Yuan Qi Lun (written in Tang Dynasty) summarizes the process of gestational human life: "Tao, the inborn entity-in-self, gave birth to Yin and Yang, Yin-Yang gave birth to heaven (Tian) and earth (Di), Tian-Di gave birth to father and mother, and father-mother gave birth to my life ... After ten months of pregnancy, then a life came from the embryo.”2

Finally, the culture of Taoist procreation does not view the phenomenon of life in isolation, but regards life to be a systemic developing process that stems from Tao at the beginning and returns to Tao at the end, which would make limited and fragile individual life become eternal and meaningful. Tian-Di of Zhuangzi points out:

At the very beginning, there was nothing in the universe, without anything and names, then One without any shape came into being and became the first existence, called Virtue (or Te, meaning the transcendental Tao to be of visualization). Te was aeriform and indivisible, called vitality, which kept moving and giving birth to everything. Everything got its existence, called body, and body kept staying with spirit, called nature. To practice the nature to return to Te, till to become the same as the original Tao.

Zhuangzi indicates that life is rooted in the potential Tao, which is an entity of Being and Non-Being. At the very beginning, Tao represented One (or Yi), a kind of Jing Qi, which ensured the primitive matrix and motive power of everything's life. With the further differentiation of active Yin-Yang, Tao-Yi evolved into a kind of human being's energy, egg and sperm (speaking in modern terms). The Yin-Yang interaction resulted in the combination of egg and sperm, thus facilitating the syncretism of body, spirit and human nature, which are essential to every life, so that the latent life further evolved into a specific life. Meanwhile, life gradually drifted away from Mother of Tao; hence, it became necessary to train one's nature to return to Tao. Thus, life came from Tao at the beginning and turned back to Tao in the end, life and Tao remaining together as a unity all the time; in this way, Taoism realizes its ultimate ideal of immortal life.

Thus, Taoism insists that human life is rooted in Tao, coming to be through the male and female's sexual random combination, and being born naturally and growing up gradually. Tao is the Divine Origin, foundation, and ultimate destination of life. The phenomenon of life is fathomless, just like a sealed book, so the best means of procreation is to be done just as Tao does, keeping Yin and Yang combining harmoniously and self-fulfilling without any artificial intervention.

\section{Differences Between Taoism and Human Cloning}

There are three main differences between Taoist conception of human reproduction and cloning. With respect to the form of reproduction, Taoism insists on natural sexual reproduction, while cloning involves artificial asexual reproduction. With respect to the being that is reproduced, Taoism insists on the unity of body and mind, taking the biological, spiritual, and social connotations of life into account seriously, while cloning focuses merely on the biological understanding of life. With respect to the meaning of reproduction, Taoism stresses not only the secular concern of life in this world, but also in the ultimate concern of transcendent life, while cloning offers only secular care without any transcendental care.

\footnotetext{
1 Tao Tsang, Volume 22, p. 616.

2 Tao Tsang, Volume 22, pp. 383-384.
} 
First, concerning the form of reproduction, cloning favors a particular genetic identity and selects artificially, while Tao is natural and thus Taoism refrains from activity contrary to nature. Life originates from the variation and evolution of Tao-Qi and is naturally procreated in the embryo. ${ }^{3}$ So it is easy to see that Taoist reproduction is based upon the random pairing of male and female.

Cloning is a form of asexual reproduction, while Taoism insists on sexual reproduction, which is regarded as the divinely true and unvarying way for the male and female both to participate in reproduction. Taoists believe that a solitary Yin cannot procreate by herself, and a widowed Yang cannot create life by himself. So as the conjoining of Tian and Di brings everything's vigor, the coupling of male and female gives birth to everything; this is the natural way. ${ }^{4}$ Therefore, objecting to the asexual reproduction that characterizes cloning, Taoism teaches that it goes against the basic law of reproducing human life, the violation of which is not only evident in terms of the potential risk in the technical process, but also in the failure of the value expectation.

The following research facts may be a serious blow to the conception of human cloning but a strong support to that of Taoist human reproduction. The related statistics indicate that the success rate of present animal cloning is only about $2 \%$. In the case of animals' natural reproduction, the ratio of genetic abnormality is less than $1 \%$, in tube propagation it is $15 \%$, while in clonal propagation it is more than $40 \%$. The lives of surrogate mothers are also endangered (HAN Yuehong, 2005, p. 244). Researches have also shown that the dream of perfectly designed and exactly copied genes through asexual reproduction would hardly come true. Genome is not the whole of human life, and cloning at most can approximatively copy the natural attributes of donors; it can do nothing about the spiritual and social attributes, which are indispensable for the constitution of human life (Borem, Santos, \& Bowen, 2003, p. 180). The perfectibility of human nature is not determined genetically; intelligence, thought, behavior, personality, ideology, moral, and even physical constitution are all closely related to postnatal environmental influence.

Next, asexual reproduction through human cloning differs from the natural process of sexual reproduction in its emphasis on selecting genetic sequences artificially and deliberately. Cloning thus focuses on human beings' biochemical composition. Just as Jeremy Rifkin notes: "We begin to look at life from the chemist's viewpoints, and organisms no longer win our attention or respect. Our interest and view to nature focuses more and more on the organism's genetic blueprint and thousands of chemical composition” (Rifkin, 2000, p. 15). That is to say, it is enough to become a person only with 46 chromosomes and 3.2 billion nucleotides (Borem, Santos, \& Bowen, 2003, p. 182). Taoism, however, not only places great emphasis on life's biological connotation, but also on its spiritual connotations; life needs not only the body, but also the spirit; only the unity of body and spirit can constitute a flourishing human life: "Human life takes the pneuma of Tian and Di, and presents to be spirit and body ... only when the spirit and the Qi are enough full, can life be born”. ${ }^{5}$ Here, body (or Qi) refers to the objective, material, extended object, while spirit refers to the unextended contemplative object. The unity of body and spirit can be called complete human, while the separation of body and spirit can only be called eidolon or ghost. $^{6}$

\footnotetext{
3 Tao Tsang, Volume 6, p. 401.

4 Tao Tsang, Volume 2, p. 987.

5 Tao Tsang, Volume 22, P385; Volume 6, p. 401.

${ }^{6}$ Tao Tsang, Volume 23, p. 646.
} 
Finally, a cloned human, as the product of technology, can only understand its life within the context of the secular world, which is the common failing of human beings brought about by modern science and technology. As George Murphy points out: "One of the most powerful challenges, formed by the rise of modern science, may be that human's understanding merely restricts in the mundane reality, but forgets the ultimate reality entirely" (Peters, Seng, \& Bennett, 2002, p. 137). What is worse, a clone is the idealistic product of genetic optimization, and a puppet manipulated by biological technology, which would easily lead to some kinds of cloned babies commercialized in the future. Ted Peters points out: “As a means to create the designed babies, the clone could possibly lead to the merchandizing and commercialization of babies, which is sure to do great harm to the dignity of babies ... It is human marketability rather than genetic uniqueness that will overturn the human sacred peculiarity of individual life” (Peters, Seng, \& Bennett, 2002, p. 178).

As a religion seeking to understand life's meaning, Taoism takes the transcendent into account, endowing mundane life with divinity and spirituality. Tai Ping Jing (written in Han Dynasty) states: "Harmony and integration of the divinity and spirituality, can it be called human” (WANG, 1960, p. 567). In the Taoist concept of life, every human life has a spiritual dimension, because a human being is the combination of soul and body. The headstream of life's spiritual dimension is Tao, the foundation of it is destiny, the corresponding representation of it is constellation, and the ultimate goal of it is immortality.

Specifically, Taoism endows human reproduction with holiness. Xuan Gang Lun (written in Tang Dynasty) states: "My life originates from Tao and is completed by gods, which makes me transcend the restriction of survive and downfall, and release my heart to the self-content land freely. Tao may be my teacher and gods may become my friends". ${ }^{7}$ It is just under the multiple care of numerous sacred god-powers that life appears to be honorable and dignified. Taoism also matches each life born into the world with a constellation of specific moral connotations, so as to further confirm the uniqueness of each life in the transcendental world. Tai Ping Jing states: "The length of human life has been dependent up on the moral connotations in the specific heaven-sent constellation connected with his past behaviors. Saintlike persons can understand the meaning: human life has been tying with the predeterminate constellation and controlled by the heaven. What the sainted can do is to strengthen the moral cultivation, and act as the natural laws” (WANG, 1960, p. 541-552).

It is the holy, transcendental connotation of each individual life, sharing the spiritual nature of Tao, and tying with the predeterminate constellation that solidifies the foundation of life, opens the infinite space of life, and makes every life in the secular world be of ultimate holiness, transcendence, and uniqueness. Taoism's theory of predeterminate constellation appears chimerical prima facie, but conceives of the full value and significance of modern life to pursue sedulously behind its deep back, which becomes the secret anguish opposing a cloned human's life, for a clone is never "ME” but a copy of others.

Taoism refrains from activity contrary to nature, which is the fundamental principle of all actions, and objects to human intervention in reproduction. The actions that human cloning does artificially to assist reproduction are all against the laws of nature. In Taoist thought, the combination of one Yin and one Yang can be called Tao, any life is the product of the natural unity of Yin and Yang, which obviously opposes artificial asexual reproduction. According to Taoism, a human being is not only biological, but also spiritual; the latter aspect of

\footnotetext{
7 Tao Tsang, Volume 23, p. 675.
} 
human nature is just ignored by cloning technology. Additionally, Taoism holds the sacred formless Tao, implying the intrinsic holography of life, as mother and father produce new life, and thereby achieve longevity and immortality in keeping with Tao and the transcendental nature of human life.

\section{The Enlightenment of Taoist Culture on Human Cloning}

Refraining from activity contrary to nature is the fundamental principle for Taoism, which applies to reproduction; cloning attempts to change the natural reproductive process by means of artificial technology. There are many profound lessons concerning humanity's antagonistic relationship to nature in classical Taoist writings, the lesson from the fable in Ying Di Wang of Zhuangzi is perhaps the most typical:

Shu was the emperor of the South Sea, Hu was the emperor of the North Sea, and Hundun was the emperor of the Center. Shu and Hu often met at the place of Hundun, who treated them very kindly. So they planned to repay Hundun for his virtues to them. They said: "People all have seven orifices, so they can see, hear, eat, and breathe. But only Hundun has none. We may try to cut the seven orifices for him.” So they began to cut one orifice a day for Hundun, but after seven days, Hundun died.

Both Shu and Hu intended to pursue quick results, while Hundun, preexistent harmony, stood for following and acting in accordance with nature, and with kindness to everything. Shu and Hu acted contrary to nature by cutting seven orifices for Hundun, which leads to the tragedy of Hundun's death. Under the guise of their subjective wishes they used technical means to destroy the perfect original nature, harmony and even life itself. "Helping" Hundun to evolve artificially and thereby causing his death is illuminating with respect to the expectation of cloning to help human beings to reproduce artificially.

First, the death of Hundun indicates that actions in violation of the laws of nature are harmful and cannot succeed. The artificial attempt to reproduce through cloning will certainly backfire for breaking the laws of natural reproduction. So far, cloning technology has proven itself to be defective and unsafe. Researches have shown that Man understands "the sealed book of life" still very superficially, and knows little about the reprogramming and expression of genes in the process of nuclear transfer. So the consequences of human cloning are really difficult to predict. To say the least, even if the technical barriers to cloning could be resolved in the future, the cloned human will still live in secret anguish all his life, for human cloning would just be stressed on human biological nature, while human sociality and spirituality would be neglected comparatively. As a result, the psychology of a cloned human will certainly be injured seriously because it is controlled completely, which may make the clone feel more pessimistic and hopeless in their social life than persons of normal birth. Some clones may become aware that their life is meaningless, for they were reproduced just for the purpose of others, and their life is nothing but to be a social tool. The stronger their consciousness of living as a social tool is, the more harmful their resistance to society will be. What is worse, if cloning technology is used for the purpose of producing the commercial human organs, to create cloned human, it is really much difficult to predict its social consequences.

Second, the death of Hundun indicates that Hundun cannot be cut at all, and there are some things that cannot be resolved through technology. In other words, science and technology are not almighty. There are some insoluble problems in human cloning, which are due to the technology itself. That is, no matter how well cloning technology may be improved and perfected in the future, human cloning will encounter some insurmountable 
biological barriers inevitably, because science alone is not able to fully account for all the dimensions of human life (Borem, Santos, \& Bowen, 2003, p. 182). Bertrand Russell asserts that science can never understand the human body, only when seeking help with principles different from physics and chemistry can the human body be understood (Russell, 1982, p. 64). Science may be helpful with human physical and chemical issues, but helpless with issues of psychology and spirituality.

In fact, due to the large number of technical setbacks, such as defects, deformities, premature senility, and so on, that have occurred in animal cloning, the success of cloning technology is doubtful. Rudolf Jaenisch also points out non-technical issues in cloning. Many of problems with animal cloning are not merely technical barriers, but serious biological barriers. The technical barriers can be improved in the future, but the biological barriers are insuperable (Han Yuehong, 2005, p. 250). Therefore, while cloning has a clear beginning, it lacks any clear end.

Finally, the death of Hundun is to raise the alarm about human's desires: Do not allow unrealistic "good" intentions to undermine the harmonious existence of nature, which may lead to the harming or murdering human beings, just as Hundun was cut to death. A cloned human being is the victim of good intentions that certain people want to achieve, such as genetic perfection through precise procreative duplication. The desire of genetic perfection is regarded to be little meaning. One reason is that the genetic differences among human individuals are infinitesimal. Biologists have discovered through studying the basic framework of the human genome that 99.9\% genes among human individuals are same, and only $0.1 \%$ genes are different. Therefore, "it is a low-level error to attribute all of our hopes and concerns to genes" (Borem, Santos, \& Bowen, 2003, p. 182) The other reason is that genes themselves are value-neutral. All genes are equal in value, and can not be classified as "good" or "bad." Even so-called "defective" genes have their own special functions. For example, researchers have found that there is a gene which can cause people to have the sickle-cell anemia, but this gene also has a preventive function with respect to malaria. From a genetic perspective, no one is perfect and certain genetic defects exist in everyone's body (HAN Xiaocheng, 2005, p. 58). In attempts at genetic selection, the relative value of specific gene functions raises the dilemma of possibly preserving one function while losing another, thereby resulting in diminishing returns. Moreover, precise copying of a human being's phenotypic traits is impossible, for cloning can only duplicate the biological attributes of the donors at most, but cannot replicate intelligence, behavior, personality and so on.

The conclusion we should derive from Taoism is that reproductive cloning should halt in front of the holy life of a human being. The Tao Te Ching states: "For the holy thing under heaven can't be tampered with. Those who tamper with it, must fail in it; and those who grab at it, must lose it.” (Tao Te Ching 29) We ought to follow Zhuangzi's exhortation: "You should let your mind wander in pure nature, tally with the indifferent Tao, follow the natural course of everything and leave your personal desire aside.”(Ying Di Wang of Zhuangzi) Holy human life is genuinely received from heaven-Tao, the same as nature, and it cannot be changed at all. ( $\mathrm{Yu}$ Fu of Zhuangzi)

Taoism’s solemn and just warning of "nature can not be changed" and "tampering must fail” are significant guiding principles concerning the future development of cloning technology. If human cloning does not follow human nature and goes its own way, which it inherently does, it is bound to lead to tragedy, just as Zhuangzi warns: “Duck's leg is short, but lengthening it will cause anxiety. Crane’s leg is long, but shortening it will cause 
misery. Therefore, what nature is long shouldn't be shortened, and what nature is short shouldn't be lengthened. Following the nature would be no sorrow.” (Pian Mu of Zhuangzi)

In addition, intensifying genes so as to lead to inequality of genes artificially is one of the purposes and drawbacks of human cloning. Taoism teaches the principles of justice and fairness. The Tao Te Ching states: "Tao of heaven would take away from the overabundance to make up for the insufficient. But Man's way is quite different, which will take away from the insufficient to add to the superfluousness.” (Tao Te Ching 77) The Taoist principles of nonmaleficence and kindness to everything, even if it has the slightest degree of life, is morally enlightening when considering the harms which can be predicted, but can not be resolved, caused by cloning technology.

In brief, the principles of respecting life, acting naturally and refraining from activity contrary to nature, justice, fairness and nonmaleficence, the uniqueness and transcendency of life, are both inspirational and provide guidance concerning human cloning's attempt to strengthen and simplify the process of human reproduction artificially by means of technology, which would result in greater harms than good to any cloned human beings.

\section{Conclusion}

Human cloning uses human beings as objects or tools of technology for the first time, thus causing human beings to lose their subjective telos and due dignity. Immanuel Kant contends that, concerning oneself or others, a human being must always be regarded in terms of its own telos, and not as an instrument. Every human being has an infinite intrinsic value, or dignity. A merely valuable thing can be replaced by other things of equivalent value. In contrast, dignity is beyond and above all values, without any equivalent, and is thus unable to be replaced by anything else (Kant, 1986, p. 87). Thus, we can see that the development of science and technology is losing both its external humanistic constraints and the internal humanistic conscience, thereby deviating from its original intention to serve humanity. In order to resolve the negative influence of the development of science and technology, or minimize its inevitable harm to human beings, we must, as John Dewey asserts, humanize science (Dewey, 1965, p. 23). The humanization of science and technology requires them to develop in a way that is oriented toward respecting, caring for, and loving human beings, and take serving human civilization and progress as their fundamental purpose.

The resources for humanizing science and technology obviously cannot be achieved from the linear and value-free development of science and technology themselves. The most effective way is to integrate the humanistic care of religion into the development of science and technology, and create a space for science and religion to learn from each other's strengths to offset its own weakness, and thereby develop together. Albert Einstein points out the interdependence between science and religion: "Science is like the lame without religion, and religion is like the blind without science” (Einstein, 1979, p. 182).

Taoism offers a successful example of the coordinated and balanced development of both the rational spirit of science and the humanistic care of religion, both instrumental and value rationality. Joseph Needham praises Taoism for offering and the most interesting combination of philosophy and religion, for being a mystical system which did not extremely oppose science (Needham, 1990, p. 35). In the application of technology, Taoism tries to organically combine techno-determinism with humanism, connecting technology with the natural Tao so as to act as Tao and ensure the principle of Tao that scientific-technological progress should serve people but not harm 
them. Therefore, in the face of the impending crisis of human cloning, Taoism is of great significance, at the level of theory, practice and future enlightenment, in exploring the related humanistic resources to actively guide modern biological technology to serve the humanity optimally.

\section{References}

Borem, A., Santos, F. R., \& Bowen, D. E. (2003). Understanding Biotechnology (Chinese Version). XI'an: Xi'an Jiaotong University Press.

Dewey, J. (1965). Problems of men (Chinese Version). Shanghai: Shanghai People’s Press.

Einstein, A. (1979). The collected works of Einstein (Vol. III) (Chinese Version). Beijing: Shangwu Press.

HAN, X. C. (2005). Science is facing a crisis: The humanities reflection on modern science and technology. Beijing: Society Press of China.

HAN, Y. H. (2005). Escorting life's dignity: On the ethics problem of modern biotechnology. Beijing: People's Press.

Kant, I. (1986). Grundlegung zur Metaphysik der Sitten (Chinese version). Shanghai: Shanghai People’s Press.

Lao-zi. (1994). Tao Te Ching. Changsha: Press of Hunan.

Needham, J. (1990). The history of Chinese science and technology (Vol. II) (Chinese Version). Beijing, Shanghai: Science Press and Shanghai Ancient Books Publishing House.

Peters, T., Seng, K. P., \& Bennett, G. (2002). Bridging Science and Religion (Chinese Version). Beijing: China Social Science Press.

Rifkin, J. (2000). The biotech century: Harnessing the gene and remaking the world (Chinese Version). Shanghai: Shanghai Science, Technology and Education Press.

Russell, B. (1982). Religion and science (Chinese Version). Beijing: Shangwu Press.

Tao Tsang. (1987). Shanghai, Beijing and Tianjin: Shanghai Bookstore Press, Cultural Relics Publishing House, Tianjin Ancient Books Publishing House.

WANG, M. (1960). Tai Ping Jing Hejiao. Beijing: Zhonghua shuju Press.

Zhuangzi. (1998). Exegesis of Nanhua Zhenching. Beijing: Zhonghua shuju Press. 